\title{
DIEZ CONSEJOS PARA ARGUMENTAR BIEN O DECÁLOGO DEL BUEN ARGUMENTADOR
}

\author{
Manuel Atienza \\ Universidad de Alicante
}

RESUMEN. Las reglas de la buena argumentación recogidas en este breve texto son tanto de carácter técnico como ético.

Palabras clave: argumentación; reglas de la argumentación.

ABSTRACT. The rules of a good argumentation which are exposed in this brief text have not only a technical but also an ethical character.

Keywords. Argumentation, rule of argumentation. 


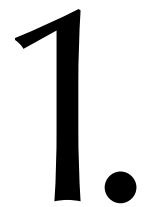

El mejor consejo que puede darse a quien desee argumentar bien en el Derecho o en cualquier otro ámbito es prepararse bien. Picasso decía que la inspiración existe pero tiene que pillarte trabajando. De manera semejante, la habilidad dialéctica, argumentativa, existe, pero tiene que pillarte preparado, conocedor del fondo del asunto. No se puede argumentar bien jurídicamente sin un buen conocimiento del Derecho, de los materiales jurídicos, y de la teoría del Derecho, de los instrumentos adecuados para manejar aquellos materiales.

2. Hay aspectos comunes a cualquier tipo de argumentación, pero también rasgos peculiares de cada campo, de cada tipo de debate. Por ejemplo, lo que es apropiado para una conferencia (la exposición por extenso de una tesis) no lo es para el que participa en una mesa redonda: una buena presentación de la tesis que se desea defender en ese tipo de debate no tiene por qué ser una "miniconferencia"; lo importante aquí no es efectuar una exposición completa, exhaustiva, sino más bien clara, razonablemente informativa, que estimule la discusión y prepare de alguna forma para, al final, persuadir al auditorio.

3. No se argumenta mejor por decir muchas veces lo mismo, ni por expresar con muchas palabras lo que podría decirse con muchas menos. La amplitud excesiva del discurso aumenta las probabilidades de cometer errores y corre el grave riesgo de provocar hastío en el oyente.

4. En una discusión, en un debate racional, esforzarse porque el otro tenga razón - como alguna vez propuso Borges- parece demasiado. Pero esforzarse por entender bien lo que el otro ha dicho es una exigencia moral —en el sentido amplio de la expresión-que resulta además bastante útil como recurso retórico o dialéctico: hace más difícil que podamos ser refutados (por ejemplo, con un «yo no he dicho eso») y aumenta las probabilidades de que nuestros contendientes estén también dispuestos a entendernos bien.

5. Cuando se argumenta en defensa de una tesis, no estar dispuesto a conceder nunca nada al adversario es una estrategia incorrecta y equivocada. Hace difícil o imposible que la discusión pueda proseguir y muestra en quien adopta esa actitud un rasgo de carácter, la tozudez, que casi nadie aprecia en los demás. No es, por tanto, un buen camino para lograr la persuasión.

6. Cuando se argumenta con otro, uno puede tener la impresión de que los argumentos de la parte contraria funcionan como una muralla contra la que chocan una y otra vez nuestras razones. Por eso, una vez probada la solidez de esa defensa, lo más aconsejable es ver si uno puede tomar la fortaleza intentando otra vía. Esa maniobra debe hacerse sin desviar la cuestión. O sea, no se trata de disparar torcido, sino de disparar desde otro lado, cambiando la posición.

7. La argumentación no está reñida con el sentido del humor, pero sí con la pérdida del sentido de la medida. Hay ocasiones en que no es apropiado hablar en broma (por ejemplo, del holocausto, del genocidio de un régimen militar...) y hay bromas y bromas. Para distinguir unas de otras, el mecanismo más simple y efectivo consiste en ponerse en el lugar del que tiene que soportar la broma.

8. No se argumenta bien por hacer muchas referencias a palabras prestigiosas, autores de moda, etc. Lo que cuenta es lo que se dice y las razones que lo avalan: 
la calidad y fortaleza de esas razones son responsabilidad exclusiva del que argumenta.

9. Frente a la tendencia, natural quizás en algunas culturas, a irse por las ramas no cabe otro remedio que insistir una y otra vez en ir al punto, en fijar cuidadosamente la cuestión.

10. En cada ocasión, hay muchas maneras de argumentar mal y quizás más de una de hacerlo bien. Este (ligero) apartamiento de la regla de la multiplicidad del error y la unicidad de la verdad se debe a que en la argumentación las cuestiones de estilo son importantes. Como ocurre con los autores literarios, cada persona que argumenta tiene su estilo propio y es él el que ha de esforzarse, primero, por encontrarlo, y luego, por elaborarlo. 